\title{
IMPLEMENTASI SENSOR ULTRASONIK PADA ROBOT PENGIKUT OBJEK DENGAN KONTROL LOGIKA FUZZY
}

\author{
Reza Nandika \\ Dosen Tetap Prodi Teknik Elektro Universitas Riau Kepulauan Batam
}

\begin{abstract}
ABSTRAK
Teknologi robot terus berkembang mengikuti kemajuan zaman, robot banyak digunakan dalam bidang industri, kesehatan maupun militer dengan tujuan mempermudah pekerjaan manusia. Robot beroda (Wheeled robots) adalah salah satu dari beberapa tipe robot yang telah banyak dilakukan penelitian dengan kegunaan dankeperluan seperti Object Following dan Tracking. Penelitian ini merancang sebuah robot pengikut objek (object following) dengan memanfaatkan sensor ultrasonik. Sensor ultrasonik yang dipergunakan sebanyak tiga unit yang di aplikasikan untuk mengetahui jarak keberadaan sebuah objek. Sensor ultrasonik pada bagian kiri dan kanan untuk mengetahui keberadaan dan jarak objek di sisi kiri dan kanan serta sebagai pengambil keputusan pergerakan robot ke kiri dan kanan. Sensor ultrasonik tengah, untuk mengetahui keberadaan dan jarak objek yang ada di depan serta sebagai pengambil keputusan pergerakan robot maju dan mundur. Logika Fuzzy dan PID di aplikasikan sebagai pengatur kecepatan robot. Pengiriman data informasi jarak objek di kirim melalui Bluetooth dan ditampilkan pada perangkat komputer atau tablet berbasis sistem operasi android. Hasil penelitian menunjukkan Sistem kendali PID lebih responsif dari pada penggunaan sistem logika fuzzy karena sistem kendali PID sangat dipengaruhi oleh error yang dihasilkan dari selisih antara settpoint dan nilai variabel yang dihasilkan pembacaan sensor ultrasonik. Data informasi yang diterima oleh komputer dapat disimpan dalam format file *.CSV untuk dilakukan proses analisa
\end{abstract}

Keywords-Robot Pengikut Objek

\section{PENDAHULUAN}

Teknologi robot terus berkembang mengikuti kemajuan zaman, robot banyak digunakan dalam bidang industri, kesehatan maupun militer dengan tujuan untuk mempermudah pekerjaan manusia. Robot merupakan suatu alat yang dapat melakukan tugas fisik, baik yang membutuhkan pengawasan ataupun tanpa pengawasan manusia.

Istilah Robot berasal dari bahasa Ceko yang berarti pekerja atau kuli. Pada tahun 1961 George C. devon mempatenkan robot pertama kali yang diberi nama UNIMATE dan pada tahun tersebut untuk pertama kali robot tersebut dibuat dan dipasang pada industry. Pada tahun 1978 diciptakan robot PUMA (Programmable Universal Machine for Assembly) yang dikembang kan oleh Unimation. Pada tahun 1980an industri robot memasuki tahap pertumbuhan yang sangat cepat dengan semakin banyaknya institusi yang memperkenalkan robotika. Pada tahun 1995 hingga sekarang muncul aplikasi robot dalam bentuk yang lebih kecil dan pertumbuhan robotika dipicu dari penelitian dan industri [1].

Belakangan ini perkembangan teknologi robot beroda (Wheeled Robots) telah berkembang dalam berbagai bidang baik dalam bidang industri dan kesehatan maupun 
militer. Berbagai penelitian robot beroda telah banyak dilakukan dengan berbagai kegunaan dan keperluan seperti object following dan tracking [2 - 10].

Robot beroda (Wheeled Robots) membutuhkan sistem untuk mengenali keadaan yang ada disekitarnya dengan menggunakan berbagai jenis sensor. Sensor yang digunakan diantaranya dengan memanfaatkan kamera [7] [8] [10], menggunkan sensor ultrasonik dan sensor inframerah serta sensor lainnya [2-6] [9].

Sistem pengendali yang digunakan untuk mengendalikan pergerakan robot diantranya menggunakan Fuzzy Logic Controller [4][9], Kalmar filter [3], serta menggunakan system ON-OFF [5].

Berdasarkan uraian di atas, dirancang suatu sistem robot beroda yang dapat mempertahankan objek terhadap jarak dan mengikuti pergerakan objek yang ada di depannya dengan menggunakan Fuzzy Logic Controller dan membandingkannya dengan PID. Komunikasi pembacaan jarak terhadap objek dikirimkan dengan komunikasi nirkabel.

Paper ini membahas sistem kendali optimal dengan logika fuzzy dan PID untuk robot pengikut objek. Data informasi jarak objek yang terbaca oleh sensor ultrasonic dan data informasi respon robot ditampilkan dan disimpan di perangkat komputer.

\section{LANDASAN TEORI}

\section{A. SENSOR ULTRASONIK}

Gelombang ultrasonik adalah gelombang acoustic memiliki daerah frekuensi di atas frekuensi pendengaran manusia. Gelombang ultrasonik berupa acoustical yaitu vibrasi mekanik yang terjadi pada gas, cairan dan medium padat. Suara yang dapat didengar oleh manusia (audiosonik) adalah gelombang suara dengan frekuensi antara $20-20.000 \mathrm{~Hz}$ [11]. Gambar 1 memperlihatkan rentang frekuensi suara.

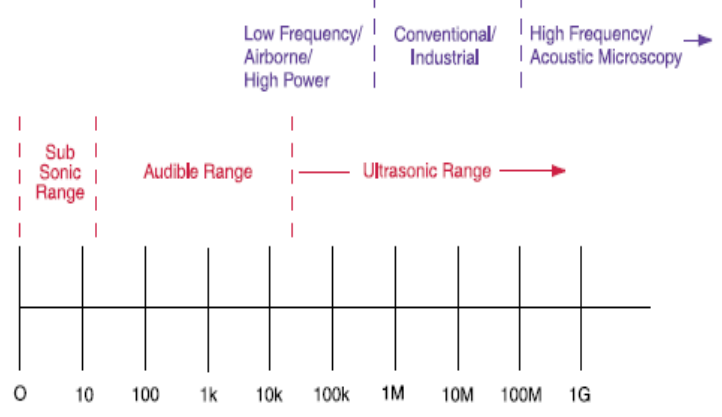

Gambar 1 Rentang Frekuensi Suara [12]

Gelombang ultrasonik membutuhkan media elastis seperti cairan dan benda padat dalam perambatan. Kecepatan ultrasound pada media elastic dengan dengan suhu dan tekanan konstan dapat dituliskan dengan persamaan 2.1 dan 2.2 [12] 


$$
\begin{aligned}
& \lambda=\frac{c}{f} \\
& \lambda=c . T
\end{aligned}
$$

Dengan :

$$
\begin{aligned}
& \lambda=\text { Panjang Gelombang } \\
& \mathrm{c}=\text { Kecepatan Material Suara } \\
& \mathrm{f}=\text { Frekuensi } \\
& \mathrm{T}=\text { Perioda Waktu }
\end{aligned}
$$

Karakteristik gelombang ultrasonik yang melalui medium mengakibatkan getaran partikel dengan medium amplitudo sejajar dengan arah rambat secara longitudinal sehingga menyebabkan partikel medium membentuk rapatan (Strain) dan tegangan (Stress). Proses kontinu yang menyebabkan terjadinya rapatan dan regangan di dalam medium disebabkan oleh getaran partikel secara periodik selama energi dan intensitas [13].

Sensor ultrasonik terdiri dari dua buah rangkaian utama, yaitu rangkaian pengirim yang disebut transmitter dan rangkaian penerima yang disebut receiver. Prinsip kerja sensor ultrasonik berdasarkan pantulan gelombang suara yang kemudian menangkapnya kembali dengan perbandingan waktu. Perbedaan waktu yang dipancarkan dan yang diterima kembali. Setelah sinyal tersebut sampai di penerima ultrasonik, kemudian sinyal tersebut akan diproses untuk menghitung jarak objek yang direfleksikan [13] [14]. Gambar 2 memperlihatkan ilustrasi perhitungan jarak antara sensor ultrasonic dengan benda yang terdeteksi. Jarak dihitung dengan menggunakan persamaan:

$$
L=\frac{1}{2} \cdot T O F \cdot c
$$

Dengan :

$$
\begin{aligned}
& \mathrm{L} \quad=\text { Jarak Objek } \\
& \mathrm{TOF}=\text { Waktu Pengukuran } \\
& \mathrm{c} \quad=\text { Cepat rambat suara }(340 \mathrm{~m} / \mathrm{s})
\end{aligned}
$$

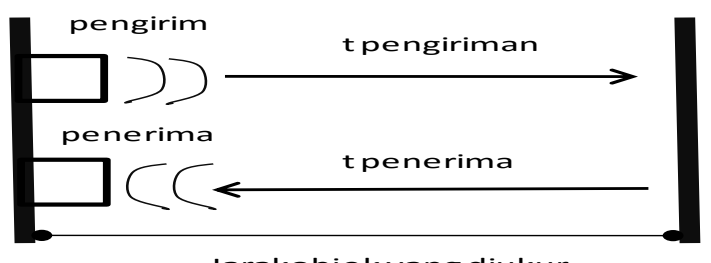

Gambar 2 Ilustrasi Pengukuran Objek

Sensor ultrasonik yang digunakan adalah sensor ultrasonik HC-SR04. Sensor ultrasonik HC-SR04 memiliki empat buah pin koneksi yaitu: pinVCC, Pin Terminal Trigger, 
Pin Echo dan Pin Ground. Gambar 3 Memperlihatkan bentuk fisik dari sensor ultrasonik HCSR04.

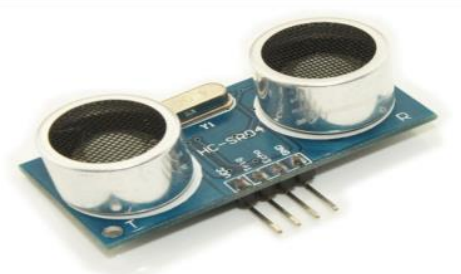

\section{Gambar 3 Sensor Ultrasonik HC-SR04}

\section{B. Mikrokontroller Arduino Uno}

Mikrokontroler merupakan sebuah chip yang di dalamnya terdapat inti prosesor, memori dan perlengkapan keluaran dan masukan. Seperti halnya komputer, mikrokontroler adalah alat yang dapat mengerjakan perintah masukan ke dalam sebuah mikrokontroler melalui sebuah program. Salah satu mikrokontroler keluaran Atmel adalah ATMega 328. Mikrokontroler ini memiliki arsitektur memisahkan memori untuk kode program dan memori untuk data, sehingga dapat memaksimalkan kerja dengan melakukan instruksi kerja secara paralel.

Arduino Uno adalah papan mikrokontroler yang berdasarkan ATmega 328. Papan mikrokontroler ini memiliki 14 digital input/output (dimana 6 digunakan sebagai output PWM), 6 input analog, resonator keramik $16 \mathrm{MHz}$, koneksi USB, jack catu daya, header ICSP dan tombol reset. Kabel USB pada arduino uno, berfungsi sebagai kabel komunikasi dan catu daya. Selain menggunakan USB sebagai catu daya, arduino uno bisa menggunakan catu daya adaptor ataupun baterai.

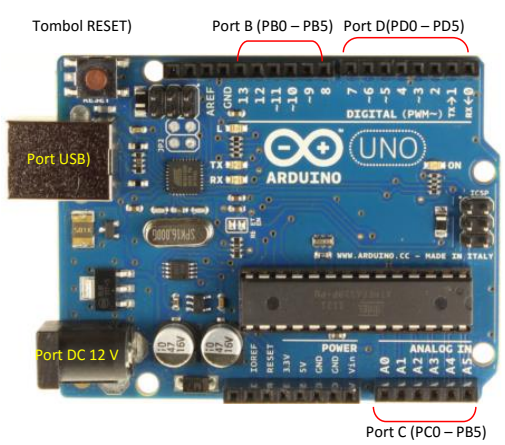

Gambar 4 Mikrokontroller Arduino Uno

C. Komunikasi Bluetooth

Bluetooth adalah salah satu teknologi pengiriman data tanpa menggunakan kabel. Bluetooth bertujuan untuk menggantikan koneksi kabel antara perangkat elektronika seperti 
telepon seluler, komputer dan perangkat lainnya. Teknologi ini memungkinkan pengguna untuk mengirimkan informasi antar perangkat secara real-time.

Bluetooth pertama kali diperkenalkan pada tahun 1994 oleh L. M. Ericson dari Swedia. Nama Bluetooth diambil dari nama seorang raja Denmark, Harald Blaatand "Bluetooth" II. Pada tahun 1998 lima perusahaan yang terdiri dari Ericson, Nokia, IBM, Toshiba dan Intel mendirikan Group of Special Interest (SIG) untuk mengembangkan komunikasi nirkabel jarak pendek (short-range). Sekarang, group ini juga dipromosikan oleh 3COM, Microsoft, Lucent dan Motorola, dan lebih dari 1900 perusahaan telah bergabung dengan SIG [15].

Bluetooth yang digunakanadalah modul Bluetooth HC-05. Modul Bluetooth HC-05 adalah modul Bluetooth SPP (Serial Port Protocol) yang dirancang sebagai komunikasi nirkabel.

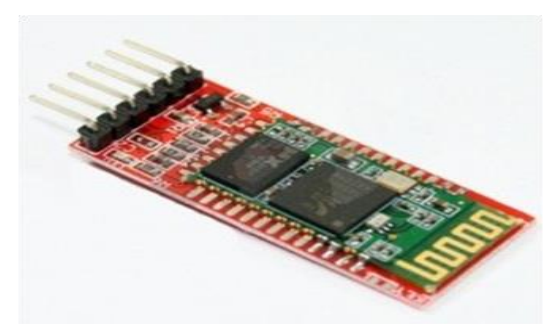

Gambar 5 Modul Bluetooth HC-05

D. Motor Servo

Motor servo adalah sebuah motor dengan sistem umpan balik tertutup, dimana posisi posisi posisi dari motor akan diinformasikan kembali kedalam rankaian kontrol yang terdapat pada motor servo.

Pengendalian putaran motor servo dapat dilakukan dengan menggunakan PWM (Pulse Width Modulation). Pada saat Ton duty cycle diberikan sebesar 1,5ms maka motor akan berhenti, jika pulsa diberikan lebih kecil dari 1,5ms motor akan bergerak searah jarum jam (CW) sedangkan jika diberikan pulsa lebih besar dari 1,5ms maka motor akan berputar berlawanan arah jarum jam (CCW) [16] [17].

Motor servo yang digunakan adalah motor servo Parallax continuous. Kecepatan rotasi dan arah ditentukan pulsa yang diberikan dalam kisaran 1,3 ms - 1,7 ms. Agar rotasi yang dihasilkan halus, servo membutuhkan jeda sebesar $20 \mathrm{~ms}$ diantara pulsa. 


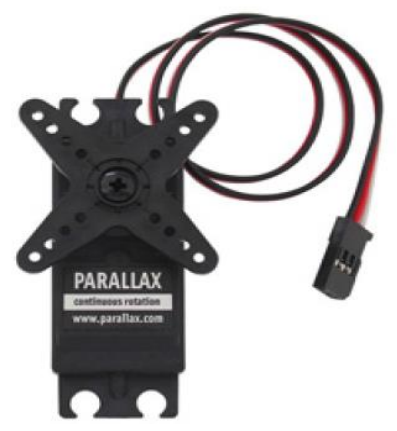

Gambar 6 Motor Servo Parallax Continuous

E. Kontrol Logika Fuzzy

Kontrol Logika fuzzy merupakan system fuzzy yang diaplikasikan secara khusus dalam bidang kendali. Kontrol logika fuzzy banyak diaplikasikan dalam system kendali karena merepresentasikan pengetahuan operator atau pakar dalam mengendalikan plant/sistem yang akan dikendalikan [18].

Kontrol logika fuzzy digunakan untuk mengatur kecepatan motor servo robot, kecepatan robot tergantung dari jarak objek yang terbaca oleh sensor ultrasonik. Tabel 1 memperlihatkan keanggotaan input dan output kontrol fuzzy.

TABEL 1 KEANGGOTAAN INPUT OUTPUT FUZZY KONTROL

\begin{tabular}{|c|c|c|c|}
\hline \multirow{2}{*}{ Gerakan } & \multirow{2}{*}{ Input } & \multicolumn{2}{|c|}{ Output } \\
\hline & & Motor Kiri & Motor kanan \\
\hline \multirow[t]{6}{*}{ Maju } & Sangat Dekat & Sangat Lambat (CCW) & Sangat Lambat $(\mathrm{CW})$ \\
\hline & Dekat & Lambat (CCW) & Lambat $(\mathrm{CW})$ \\
\hline & Agak Jauh & Agak Lambat (CCW) & Agak Lambat (CW) \\
\hline & Normal & Normal (CCW) & Normal $(\mathrm{CW})$ \\
\hline & Jauh & Cepat (CCW) & Cepat (CCW) \\
\hline & Sangat Jauh & Sangat Cepat (CCW) & Sangat Cepat $(\mathrm{CW})$ \\
\hline \multirow[t]{6}{*}{ Mundur } & Sangat Dekat & Sangat Cepat (CW) & Sangat Cepat (CCW) \\
\hline & Dekat & Cepat (CW) & Cepat (CCW) \\
\hline & Agak jauh & Agak Cepat (CW) & Agak Cepat (CCW) \\
\hline & Normal & Normal (CW) & Normal (CCW) \\
\hline & Jauh & Lambat (CW) & Lambat (CCW) \\
\hline & Sangat Jauh & Sangat Lambat (CW) & Sangat Lambat (CCW) \\
\hline Berhenti & Referensi & Berhenti & Berhenti \\
\hline
\end{tabular}

F. PID

Pengendali PID bekerja dengan melakukan koreksi terhadap error. Algoritma PID terdiri dari tiga bagian yaitu Proportional, Integral dan Derivative. Proportional menentukan reaksi secara langsung terhadap error, bagian integral menentukan reaksi terhadap akumulasi error dan bagian derivative bereaksi terhadap perubahan error yang terjadi terhadap sistem.

Untuk merancang sistem PID, kebanyakan dilakukan dengan metode coba-coba atau trial \& error. Hal ini disebabkan karena parameter Kp, Kid an Kd tidak independent. Untuk 
mendapatkan aksi kontrol yang baikdiperlukan langkah coba-coba dengan kombinasi antara P, I dan D sampai menemukan nilai Kp, Kid an Kd seperti yang diinginkan [19].

\section{Metodologi Penelitian}

A. Alat dan Bahan

Peralatan pendukung untuk perangkat keras:

- Digital multimeter

- Scopemeter

- Stopwatch

- Tollsett elektronik

- Bor tangan

- Sumber catudaya

- Komputer, sebagai alat pembuatan program, dengan sistem operasi Microsoft Windows Seven Ultimate Edition.

Peralatan pendukung utuk pembuatan program:

- Software untuk pemograman mikrokontroler

- Bluetooth terminal software

- Tera Term software

Beberapa bahan yang digunakan:

- Modul Mikrokontroler Arduino Uno

- Tiga buah Sensor Ultrasonik

- Modul Bluetooth

- Dua buah Motor Servo Continuous

- Mekanik dan Casis Robot

- Komponen elektronika lainnya

\section{B. Jalannya Penelitian}

Jalannya penelitian mengikuti alur pada Gambar 7. Pertama melakukan persiapan alat dan bahan yang akan dipergunakan. Keduan melakukan instalasi sensor ultrasonik pada papan arduino yang terdiri dari tiga buah sensor ultrasonik, kemudian melakukan pembuatan program pengukuran jarak objek menggunakan sensor ultrasonik.

Persiapan Alat dan Bahan

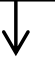

Instalasi dan Pembuatan Program Ultrasonik 


\section{Gambar 7 Alur Diagram Proses Penelitian}

Langkah ketiga, instalasi modul Bluetooth dan membuat program komunikasi Bluetooth untuk mengirim data informasi jarak objek yang terukur oleh sensor ultrasonik. Langkah keempat, melakukan instalasi software tampilan data informasi yang dikirim menggunakan komunikasi Bluetooth. Langkah kelima, melakukan instalasi motor servo pada papan arduino dan kalibrasi motor servo. Langkah keenam, melakukan pembuatan program pengaturan kecepatan motor servo berdasarkan data informasi jarak pengukuran objek oleh sensor ultrasonik. pengaturan kecepatan motor menggunakan dua metode, yaitu menggunakan kontrol logika fuzzy dan kontrol PID.

C. Perancangan Sistem

Robot dirancang agar mampu mengikuti gerakan objek yang ada di depannya dengan cara mengunci jarak antara robot dan objek. Kendali kecepatan gerakan robot menggunakan Fuzzy Logic Controller (FLC) dan PID controller. Data informasi hasil pengukuran dikirimkan melalui sistem nirkabel menggunakan komunikasi Bluetooth.

Sistem perancangan robot pengikut objek ini terdiri dari dua bagian utama. Bagian pertama adalah sistem penggerak atau mekanik robot, bagian kedua adalah sistem informasi data pengukuran jarak objek yang terukur oleh sensor ultrasonik. Bagian sistem penggerak robot terdiri dari tiga buah sensor ultrasonik, mikrokontroler, modul Bluetooth dan dua buah motor servo kontinu. Bagian sistem informasi data pengukuran berupa perangkat komputer atau telephone berbasis sistem operasi Android. 


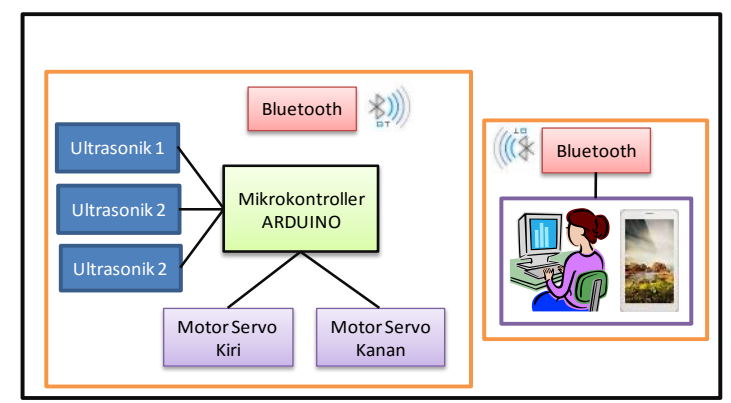

Gambar 8 Blok Diagram Perancangan Sistem

Robot yang dirancang adalah robot beroda tiga, dua roda belakang robot dikopel pada motor servo kontinu, sedangkan roda depan dibuat bebas bergerak mengikuti pergerakan roda belakang robot. Gerakan robot berdasarkan hasil pengukuran objek oleh sensor ultrasonik. Pergerakan robot maju, dengan menggerakkan servo pada roda kiri berputar berlawanan arah jarum jam $(\mathrm{CCW})$ dan menggerakkan servo pada roda kanan berputar mengikuti arah jarum jam $(\mathrm{CW})$. Gerakan mundur dengan menggerakkan servo motor kiri mengikuti arah jarum jam (CW) dan menggerakkan servo motor kanan berlawanan arah jarum jam (CCW). Gerakan robot menuju arah kiri dengan cara menghentikan gerakan servo kiri dan menggerakkan servo kanan searah jarum jam. Gerakan robot yang menuju arah kanan dilakukan dengan cara menghentikan pergerakan servo kanan dan menggerakkan servo kiri berlawanan arah jarum jam.
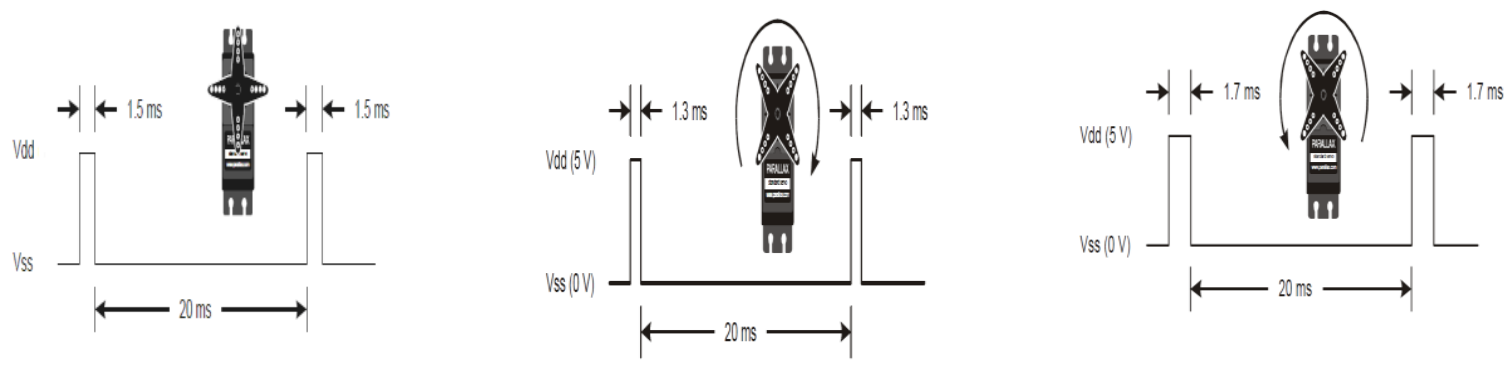

Gambar 9 Diagram Waktu Motor Servo

Sensor ultrasonik yang digunakan adalah HC-SR04. Untuk memulai, dibutuhkan pulsa sebesar $10 \mathrm{uS}$ sebagai masukan trigger, dan kemudian modulasi akan mengirimkan trigger sederet sinyal ultrasonik dengan besar $40 \mathrm{kHz}$, sinyal yang dipancarkan akan memantul dan diterima kembali. Sensor ultrasonik yang digunakan diletakkan dengan sudut masing-masing sensor sebesar $30^{\circ}$. Pulsa diberikan ke sensor ultrasonik secara bergantian dan terus menerus dari kiri tengah dan kanan. Pembacaan hasil pengukuran sensor ultrasonik dikirim melalaui Bluetooth ke perangkat komputer atau tablet berbasis Android. 


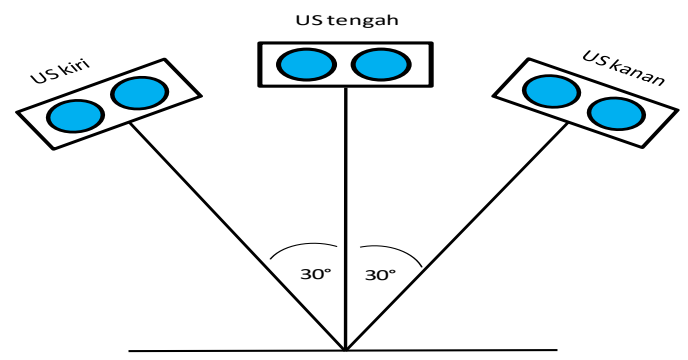

Gambar 10 Konfigurasi Sudut Sensor Ultrasonik

Dalam pengenalan objek, jarak yang terdekat diantara ketiga sensor ultrasonik merupakan acuan robot untuk mengenali objek. Jika terdapat pembacaan pengukuran objek yang sama diantara ketiga sensor, maka sensor ultrasonik posisi tengah yang menjadi prioritas.

Robot akan mempertahankan jarak yang menjadi acuan (jarak referensi). Jika jarak pembacaan sensor melebihi jarak acuan, robot akan bergerak maju dan jika jarak pembacaan sensor kurang dari jarak referensi, robot akan bergerak mundur menjauhi objek. Robot akan berhenti bergerak jika telah mendapatkan jarak referensi dari pembacaan sensor ultrasonik. Jika objek bergerak kearah kanan, sesensor ultrasonik kanan akan mendapatkan data pengukuran objek, sehingga robot akan bergerak ke kanan demikian juga jika objek bergerak ke arah kiri, sensor ultrasonik kiri akan mendapatkan data pengukuran objek, sehingga robot akan bergerak ke arah kiri. Kecepatan pergerakan robot untuk maju ataupun mundur dipengaruhi oleh pembacaan jarak sensor.

Untuk menampilkan jarak yang terbaca, digunakan komunikasi Bluetooth. Bluetooth yang digunaan adalah Modul Bluetooth HC-05. Modul Bluetooth HC-05 merupakan sebuah modul yang sangat mudah digunakan sebagai Bluetooth SPP (Serial Port Protocol). Gambar 11 memperlihatka robot pengikut objek yang di hasilkan.

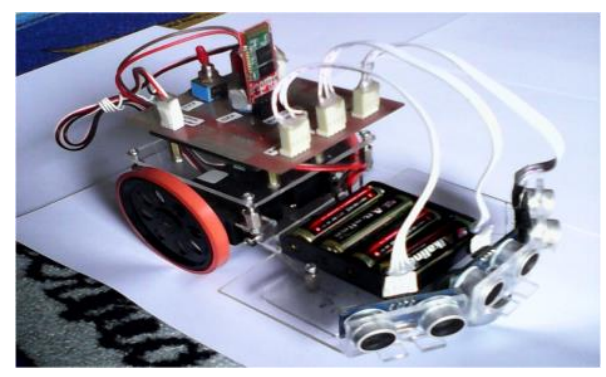

Gambar 11 Robot pengikut objek

D. Pengujian Kecepatan Robot

1) Pengujian Kecepatan Robot Tanpa Beban

Pengujian kecepatan robot tanpa beban dilakukan dengan cara menghitung berapakan nilai RPM (rata-rata per menit) putaran motor servo kiri dan kanan robot berdasarkan nilai 
masukan PWM motor servo. Percobaan ini dilakukan dengan cara memberikan nilai masukan PWM pada motor servo dengan berbagai variasi nilai masukan. Tabel 1 memperlihatkan variasi masukan PWM motor servo.

TABEL 1 MASUKAN PWM MOTOR SERVO

\begin{tabular}{|c|l|l|}
\hline $\begin{array}{c}\text { Gerakan } \\
\text { Robot }\end{array}$ & \multicolumn{2}{|c|}{$\begin{array}{c}\text { PWM Servo } \\
(\boldsymbol{\mu S})\end{array}$} \\
\cline { 2 - 3 } & Kiri & Kanan \\
\hline Maju & 1520 & 1480 \\
& 1540 & 1460 \\
& 1560 & 1440 \\
& 1580 & 1420 \\
& 1600 & 1400 \\
& 1700 & 1300 \\
\hline Mundur & 1480 & 1520 \\
& 1460 & 1540 \\
& 1440 & 1560 \\
& 1420 & 1580 \\
& 1400 & 1600 \\
& 1300 & 1700 \\
\hline Stop & 1500 & 1500 \\
\hline
\end{tabular}

Setiap masukan PWM pada motor servo dihitung berapa jumlah RPM yang dihasilkan. Dengan mengetahui diameter roda robot dan berapa besar RPM yang dihasilkan dari setiap masukan PWM maka dapat diketahui berapa kecepatan robot. Kecepatan yang dihasilkan merupakan kecepatan robot tanpa beban.

2) Pengujian Kecepatan Robot dengan Beban

Untuk mendapatkan data informasi kecepatan real dari robot pada saat bergerak maju dan saat bergerak mundur, maka dilakukan pengujian dengan beban. Cara pengujian dengan memberikan nilai masukan PWM pada motor servo dengan berbagai variasi nilai masukan, kemudian dihitung waktu yang dibutuhkan robot untuk menempuh jarak yang telah ditentukan. Gambar 12 memperlihatkan skenario pengujian dengan beban.

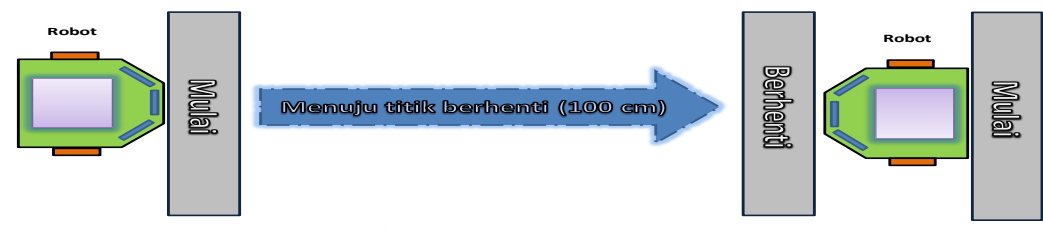

(a)

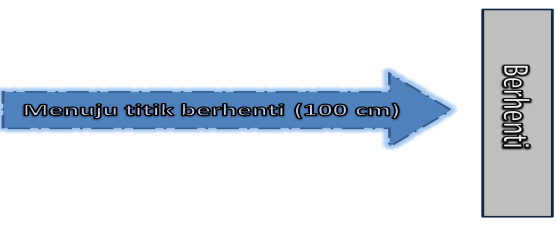

(b)

Gambar 12 Pengujian Kecepatan dengan Beban

(a) Pengujian Kecepatan Robot Maju

(b) Pengujian Kecepatan Robot Mundur

E. Pengujian Respon Robot 
Pengujian respon robot bertujuan untuk mendapatkan data informasi kecepatan dan waktu respon robot terhadap pergeseran objek

1) Pengujian Respon Robot Skenario Pertama

Pengujian dilakukan dengan cara menggeser objek yang terdeteksi oleh robot, sehingga pembacaan pengukuran jarak objek yang terdeteksi oleh sensor ultrasonik akan berubah-ubah sesuai jarak pergeseran objek. Gambar 13 memperlihatkan skenario pengujian robot pengikut objek.

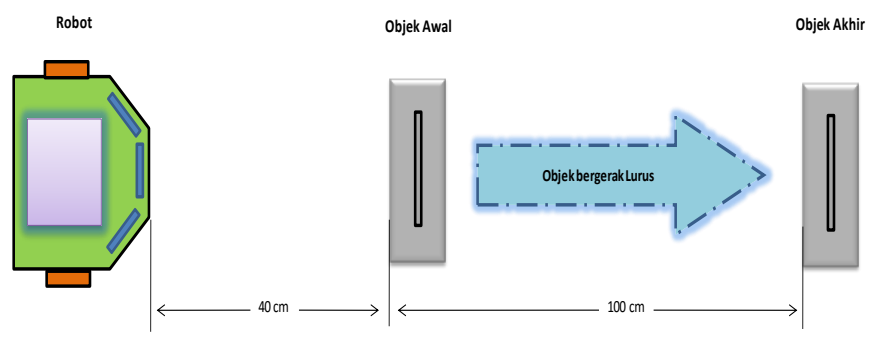

(a)

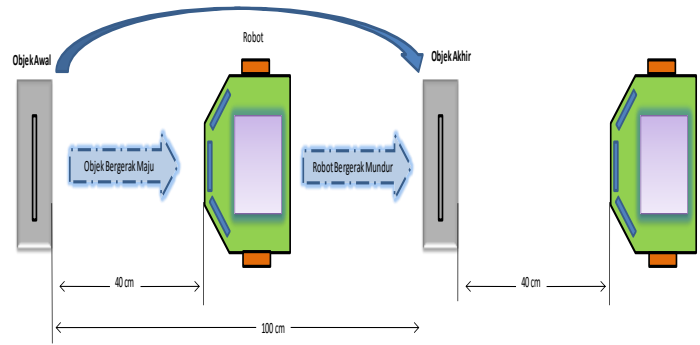

(b)

Gambar 13 Pengujian Robot Skenario Pertama

(a) Skenario Robot Maju

(b) Skenario Robot Mundur

Skenario Gerakan robot maju dilakukan dengan cara menmpatkan suatu objek di depan robot dengan jarak $40 \mathrm{~cm}$, yang merupakan jarak referensi. Objek kemudian digeser menjauhi robot dengan jarak pergeseran $100 \mathrm{~cm}$, robot akan bergerak mengikuti objek dan berhenti saat memperoleh jarak referensi.

Skenario Gerakan robot mundur dilakukan dengan cara menempatkan objek didepan robot dengan jarak $40 \mathrm{~cm}$. Objek Kemudian digeser mendekati robot hingga mencapai titik akhir yaitu sebesar $100 \mathrm{~cm}$. Robot akan bergerak menjauhi objek dengan kecepatan sesuai dengan perubahan jarak yang terbaca oleh sensor ultrasonik. Aplikasi perangkat lunak Tera Term digunakan untuk mencatat data informasi pembacaan yang diperoleh dari pengujian skenario pertama dan skenario ke dua.

2) Pengujian Respon Robot Skenario Ke dua

Pengujan gerakan robot maju, dilakukan dengan cara meletakkan suatu objek di depan robot dengan beberapa variasi jarak yaitu: $50 \mathrm{~cm}, 70 \mathrm{~cm}, 80 \mathrm{~cm}, 90 \mathrm{~cm}$ dan $100 \mathrm{~cm}$ pada saat keadaan robot belum diaktifkan. Robot diaktifkan setelah posisi objek dan robot dalam posisi yang sesuai dengan variasi jarak yang telah ditentukan.

Pengujian gerakan robot mundur, dilakukan dengan cara meletakkan suatu objek di depan robot dengan jarak $3 \mathrm{~cm}$ dengan keadaan robot belum diaktifkan. Robot diaktifkan 
setelah posisi robot dan objek sesuai dengan jarak yang ditentukan. Gambar 14 memperlihatkan pengujian robot skenario ke dua.

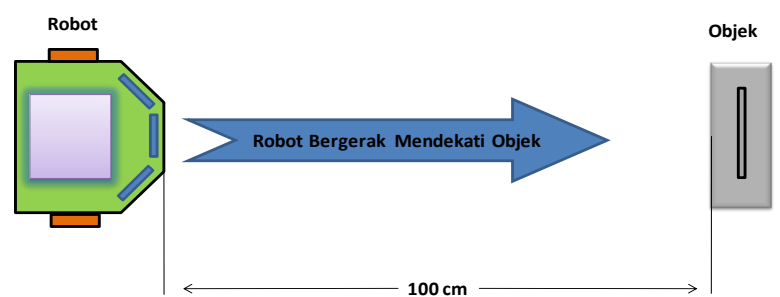

(a)

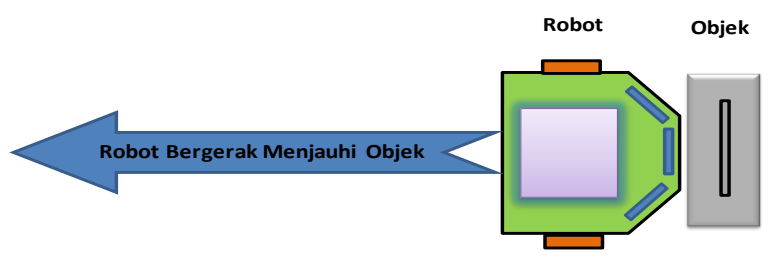

(b)

Gambar 14 Pengujian Robot Skenario Ke dua

(a) Skenario Robot Maju

(b) Skenario Robot Mundur

A. Hasil Pengujian Kecepatan Robot

1) Pengujian Kecepatan Robot Tanpa Beban

Hasil pengujian kecepatan robot tanpa beban diperlihatkan Tabel 2.

\section{TABEL 2 KECEPATAN ROBOT TANPA BEBAN}

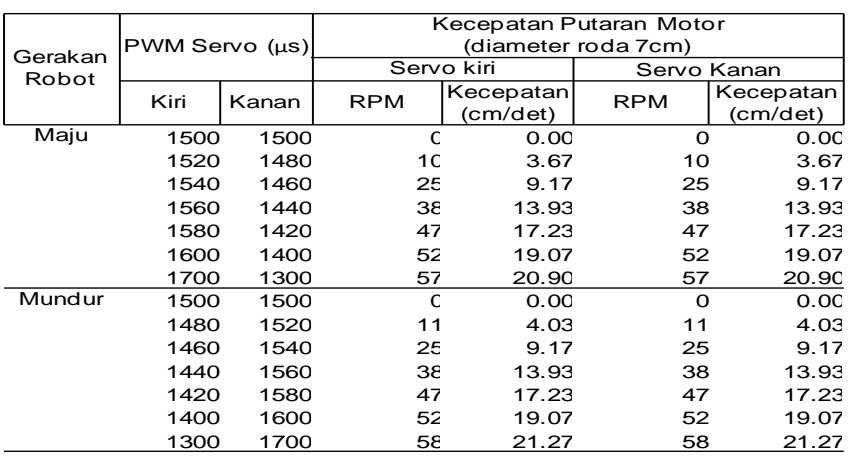

2) Pengujian Kecepatan Robot dengan Beban

Data informasi pengujian robot dengan beban ditampilkan pada Tabel 3

TABEL 3 KECEPATAN ROBOT DENGAN BEBAN

\begin{tabular}{|c|c|c|c|c|}
\hline \multirow{2}{*}{$\begin{array}{c}\text { Gerakan } \\
\text { Robot }\end{array}$} & \multicolumn{2}{|c|}{ PWM Servo $(\mu \mathrm{s})$} & \multirow{2}{*}{$\begin{array}{l}\text { Waktu Tempuh per } \\
100 \mathrm{~cm} \text { (detik) }\end{array}$} & \multirow{2}{*}{$\begin{array}{c}\text { Kecepatan } \\
\text { Robot }(\mathrm{cm} / \text { det })\end{array}$} \\
\hline & Kiri & Kanan & & \\
\hline & 1500 & 1500 & 0,00 & 0,00 \\
\hline & 1520 & 1480 & 32,32 & 3,09 \\
\hline & 1540 & 1460 & 13,14 & 7,61 \\
\hline & 1560 & 1440 & 8,96 & 11,16 \\
\hline & 1580 & 1420 & 7,08 & 14,12 \\
\hline & 1600 & 1400 & 6,04 & 16,56 \\
\hline & 1700 & 1300 & 5,56 & 17,99 \\
\hline \multirow[t]{7}{*}{ Mundur } & 1500 & 1500 & 0,00 & 0,00 \\
\hline & 1480 & 1520 & 33,51 & 2,98 \\
\hline & 1460 & 1540 & 13,31 & 7,51 \\
\hline & 1440 & 1560 & 9,05 & 11,05 \\
\hline & 1420 & 1580 & 7,15 & 13,99 \\
\hline & 1400 & 1600 & 6,17 & 16,21 \\
\hline & 1300 & 1700 & 5.50 & 1818 \\
\hline
\end{tabular}


Berdasarkan Tabel 3, dapat digambarkan grafik hubungan antara kecepatan yang dihasilkan berdasarkan masukan PWM salah satu roda robot, seperti yang ditampilkan Gambar 15.

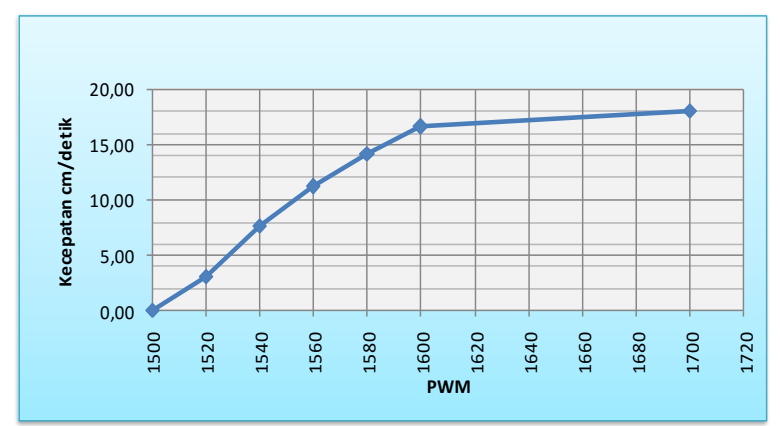

Gambar 15 Hubungan PWM dengan Kecepatan Robot

B. Pengujian Respon Robot

1) Pengujian Respon Robot Skenario Pertama

Pengujian respon robot skenario pertama dilakukan untuk mendapatkan data informasi respon robot maju dan respon robot mundur. Hasil pengujian robot bergerak maju mendekati objek diperlihatkan Gambar 16 dan Gambar 17

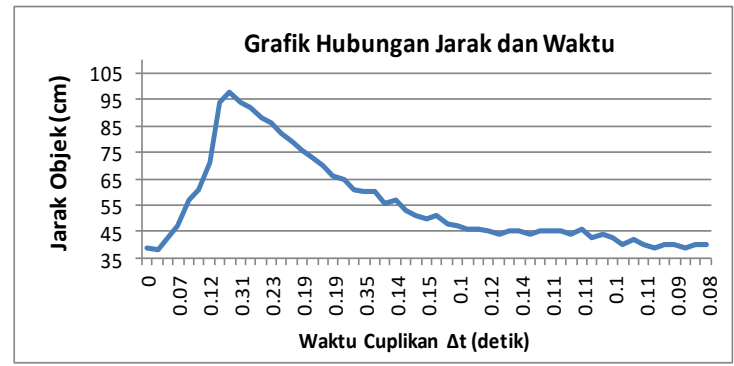

Gambar 16 Grafik Hubungan Waktu dan Jarak Robot Bergerak Mengikuti Pergeseran Objek dengan Logika Fuzzy

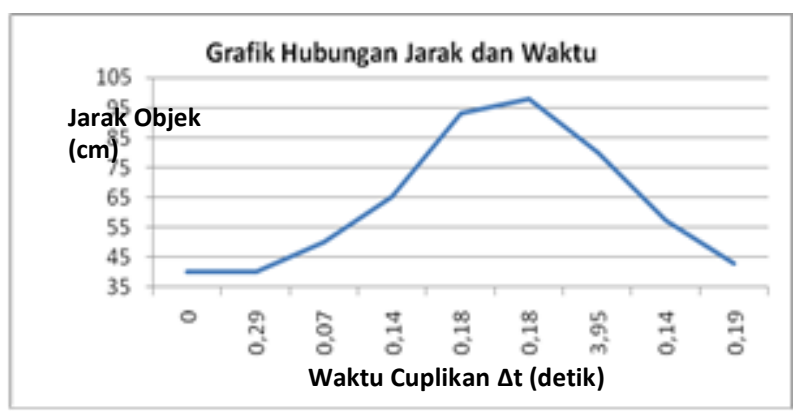

Gambar 17 Grafik Hubungan Waktu Cuplik dan Jarak Objek Robot

Bergerak Mengikuti Pergeseran Objek dengan PID

Berdasarkan Grafik data informasi Gambar 16 dan Gambar 17 yang dihasilkan, dapat diketahui waktu yang dibutuhkan robot mengikuti gerakan objek yang memiliki jarak 
pergeseran $100 \mathrm{~cm}$. Waktu yang dibutuhkan robot dengan logika fuzzy adalah sebesar 9,14 detik dan waktu yang dibutuhkan robot menggunakan PID dengan toleransi $10 \%$ adalah sebesar 5,14 detik.

Hasil pengujian robot bergerak mundur menghindari objek diperlihatkan Gambar 18 dan Gambar 19.

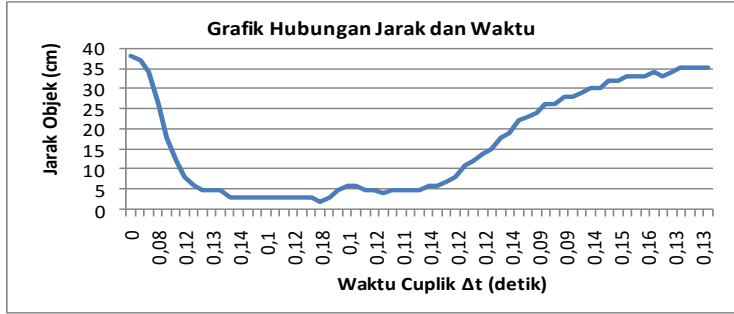

Gambar 18 Grafik Hubungan Waktu Cuplik dan Jarak Objek Robot Bergerak Menghindari Objek dengan Logika Fuzzy

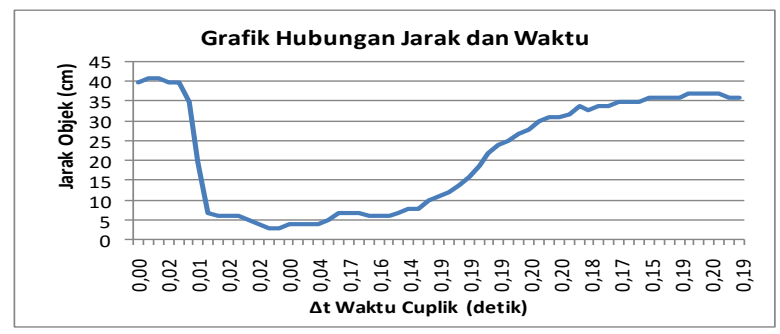

Gambar 19 Grafik Hubungan Waktu Cuplik dan Jarak Objek Robot Bergerak Menghindari Objek dengan PID

Berdasarkan grafik data informasiGambar 18 dan Gambar 19, dapat diketahui waktu yang dibutuhkan robot saat pergeseran objek mendekati robot dan robot bergerak menjauhi objek hingga mencapai titik refesensi. Waktu yang dibutuhkan robot denganmenggunakan logika fuzi adalah sebesar 7,57 detik dan waktu yang dibutuhkan robot menggunakan PID dengan toleransi $10 \%$ adalah sebesar 8,22 detik.

2) Pengujian Respon Robot Skenario ke Dua

Hasil pengujian respon robot skenario ke dua untuk gerakan robot bergerak maju mendekati robot ditampilkanpada Gambar 20 sampai Gambar 27.

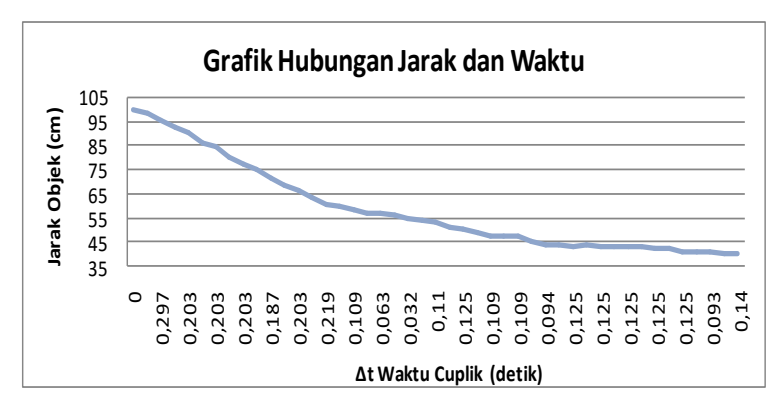

Gambar 20 Grafik Hubungan Waktu Cuplik dan Jarak Objek Robot Bergerak Maju Mendekati Objek Berjarak $100 \mathrm{~cm}$ dengan Logika Fuzzy 


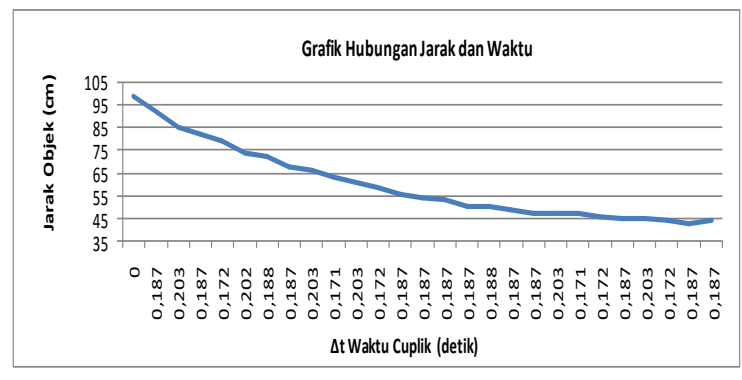

Gambar 21 Grafik Hubungan Waktu Cuplik dan Jarak Objek Robot Bergerak Maju Mendekati Objek $100 \mathrm{~cm}$ dengan PID

Berdasarkan grafik data informasi Gambar 20 dan Gambar 21 yang dihasilkan, dapat diketahui waktu yang dibutuhkan robot mendekati objek dengan jarak $100 \mathrm{~cm}$. Waktu yang dibutuhkan robot dengan logika fuzzy adalah sebesar 6,162 detik dan waktu yang dibutuhkan robot menggunakan PID dengan toleransi 10\% adalah sebesar 4,867 detik.

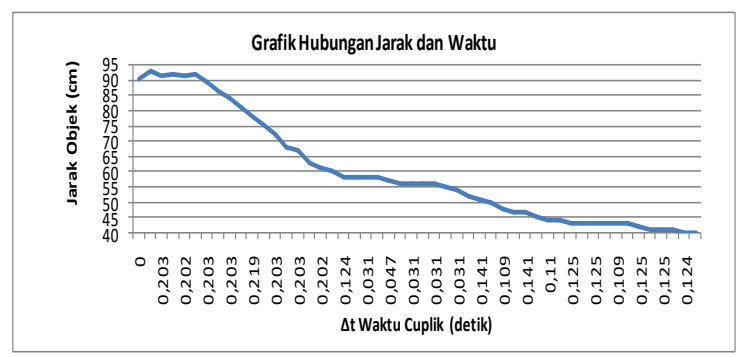

Gambar 22 Grafik Hubungan Waktu Cuplik dan Jarak Objek Robot Bergerak Maju Mendekati Objek Berjarak $90 \mathrm{~cm}$ dengan Logika Fuzzy

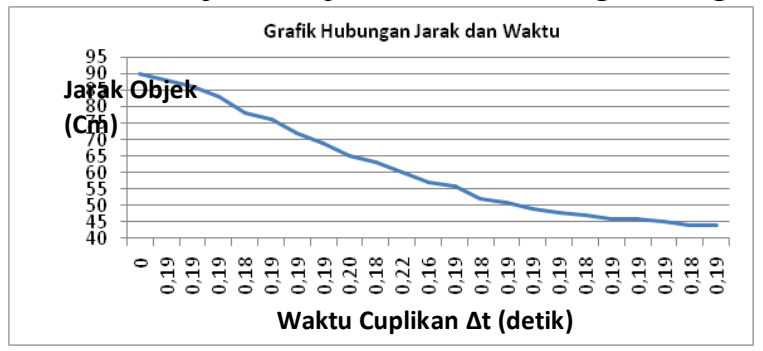

Gambar 23 Grafik Hubungan Waktu Cuplik dan jarak Objek Robot Bergerak Maju Mendekati Objek Berjarak $90 \mathrm{~cm}$ dengan PID

Berdasarkan Grafik data informasi Gambar 22 dan Gambar 23 yang dihasilkan, dapat diketahui waktu yang dibutuhkan robot mendekati objek dengan jarak $90 \mathrm{~cm}$. Waktu yang dibutuhkan robot dengan logika fuzzy adalah sebesar 6,302 detik dan waktu yang dibutuhkan robot menggunakan PID dengan toleransi 10\% adalah sebesar 4,14 detik. 


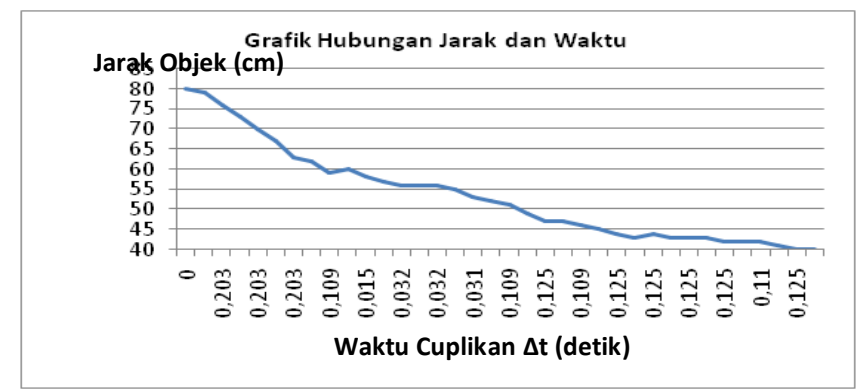

Gambar 24 Grafik Hubungan Waktu Cuplik dan Jarak Objek Robot Bergerak Maju Mendekati Objek Berjarak $80 \mathrm{~cm}$ dengan Logika Fuzzy

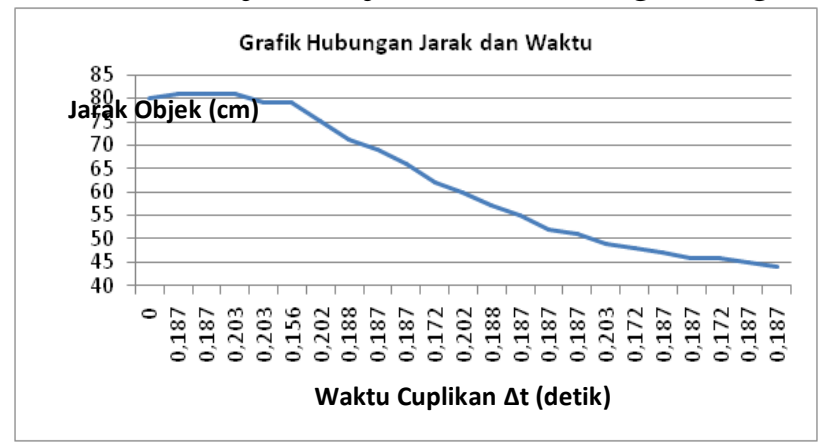

Gambar 25 Grafik Hubungan Waktu Cuplik dan Jarak Objek Robot Bergerak Maju Mendekati Objek Berjarak $80 \mathrm{~cm}$ dengan PID

Berdasarkan grafik data informasi Gambar 24 dan Gambar 25 yang dihasilkan, dapat diketahui waktu yang dibutuhkan robot mendekati objek dengan jarak $80 \mathrm{~cm}$. Waktu yang dibutuhkan robot dengan logika fuzzy adalah sebesar 4,196 detik dan waktu yang dibutuhkan robot menggunakan PID dengan toleransi 10\% adalah sebesar 4,118 detik.

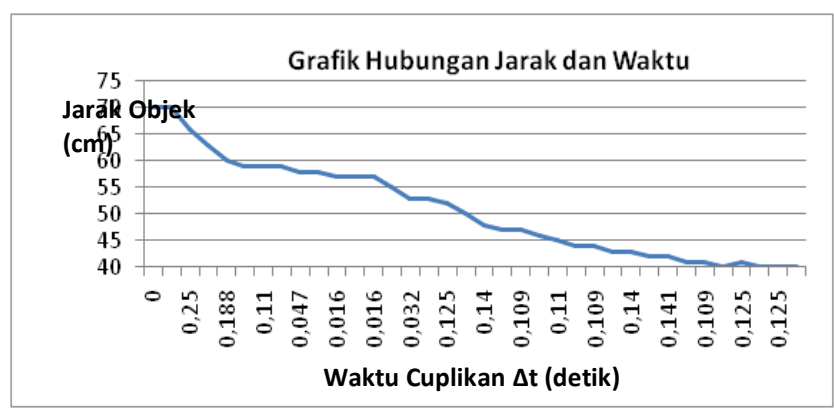

Gambar 26 Grafik Hubungan Waktu Cuplik dan Jarak Objek Robot Bergerak Maju Mendekati Objek Berjarak $70 \mathrm{~cm}$ dengan Logika Fuzzy

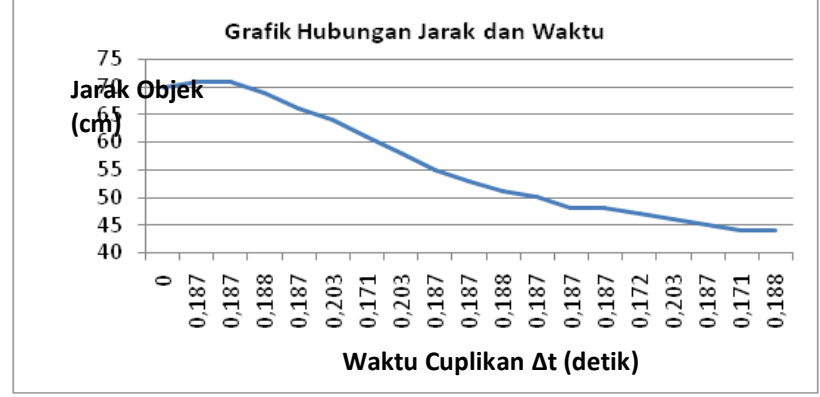

Gambar 27 Grafik Hubungan Waktu Cuplik dan Jarak Robot Bergerak Maju Mendekati Objek Berjarak $70 \mathrm{~cm}$ dengan PID 
Berdasarkan grafik data informasi Gambar 26 dan Gambar 27 yang dihasilkan, dapat diketahui waktu yang dibutuhkan robot mendekati objek dengan jarak $70 \mathrm{~cm}$. Waktu yang dibutuhkan robot dengan logika fuzzy adalah sebesar 3,635 detik dan waktu yang dibutuhkan robot menggunakan PID dengan toleransi 10\% adalah sebesar 3,37 detik.

Pengujian skenario ke dua juga dilakukan untuk mengetahui berapa waktu yang dibutuhkan robot untuk bergerak mundur menjauhi objek. Gambar 28 dan Gambar 29 memperlihatkan Grafik data informasi hasil pengujian.

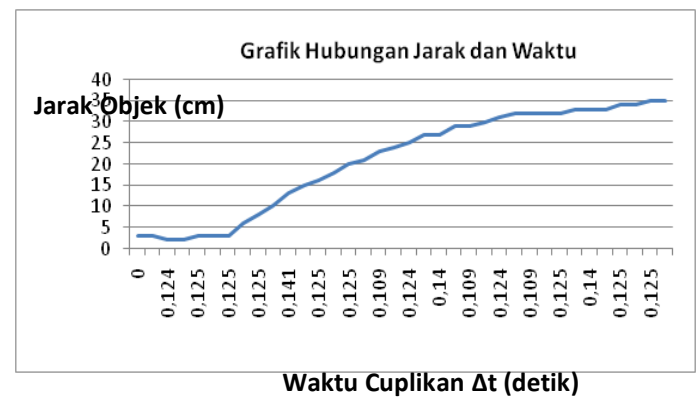

Gambar 28 Grafik Hubungan Waktu Cuplik dan Jarak Objek Robot Bergerak Mundur Menjauhi Objek dengan Logika Fuzzy

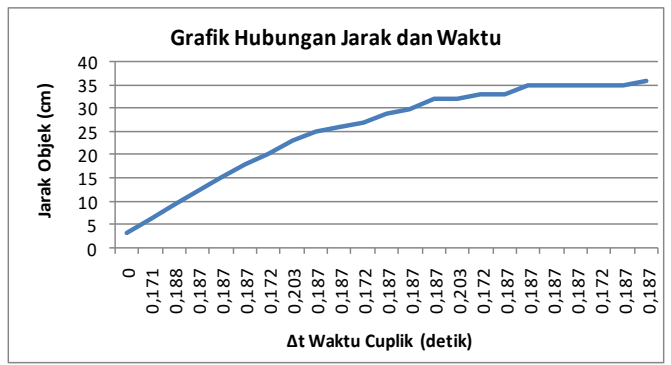

Gambar 29 Grafik Hubungan Waktu Cuplik dan Jarak Robot Bergerak Mundur Menjauhi Objek dengan PID

Berdasarkan grafik data informasi Gambar 28 dan Gambar 29 yang dihasilkan, dapat diketahui waktu yang dibutuhkan robot bergerak mundur menjauhi objek dengan jarak objek $3 \mathrm{~m}$. Waktu yang dibutuhkan robot menggunakan fuzzy adalah 4,242 detik dan waktu yang dibutuhkan robot menggunakan PID dengan toleransi 10\% adalah sebesar 4,071 detik.

\section{KESIMPULAN}

Hasil penelitian menunjukkan, dengan memberikan toleransi sebesar $10 \%$ Sistem kendali PID lebih responsif dari pada penggunaan sistem logika fuzzy karena sistem kendali PID sangat dipengaruhi oleh error yang dihasilkan dari selisih antara settpoint dan nilai variabel yang dihasilkan pembacaan sensor ultrasonik. Data informasi yang diterima oleh komputer dapat disimpan dalam format file *.CSV untuk dilakukan proses analisa.

Dapat dipergunakan metode dengan menggabungkan kontrol logika fuzzy dengan kontrol PID, diharapkan dapat menghasilkan performa robot yang lebih baik. 
Mengaplikasikan beberapa sensor lain sebagai masukan robot, seperti sensor akselerometer, sensor warna, sehingga pengenalan objek lebih spesifik.

Referensi

[1] Vikram Kapila. Introduction to Robotics. [Online]. http://mechatronics.poly.edu/smart/Archive/intro_to_rob/Intro2Robotics.pdf.

[2] Marco Susic, Stevica Graovac and Dusko Katic Aleksandar Cosic, "Combine Controller Architecture for LeaderFollower Robot Formation Control," Symposium onNeural Network Aplication in Electrical Engineering, IEEE, vol. 11, pp. 47-52, September 2012.

[3] Jae Hoon Lee, Byung-Ju Yi, Il Hong Suh, Shin'ichi Yuta, and Si Tae Noh Eui-Jung Jung, "Marathoner Tracking Algorithms for a High Speed Mobile Robot," IEEE/RSJ International Conference on Intelligent Robots and System, September 25-30 2011.

[4] Qurban Ullah, Furqan Ullah, and Seoyong Shin Irfan Ullah, "Integrated Collision Avoidance and Tracking System for Mobile Robot," IEEE, 2012.

[5] Qurban Ullah, Furqan Ullah, and Seoyong Shin Irfan Ullah, "Mobile Robot Navigation with Distance Control," IEEE, 2012.

[6] HyungSeop Lim, YoSeop Hwang, and JangMyung Lee KyoungHwan Kim, "Object-tracking robot using ultrasonic sensor and servo motor," The Fourth International Conference on Smart IT Aplications, vol. 1, September 2012.

[7] Shuji Harimoto, Takeshi Saitoh, Ryosuke Konishi Naoki Tsuda, "Mobile Robot with Following and Returning Mode," IEEE Internationa Symposium on Robot and Human Interactive Communication, Sept. 27 - Oct. 22009.

[8] Chung-Ting Li, Chwn-Chien Hsu and Ching-Ming Hong Po-Thing Huang, "Object Following Based on SURF for Mobile Robot," IEEE Global Conference on Consumer Electronics, 2012.

[9] Furqan Ullah, Qurban Ullah Irfan Ullah, "Real-time Object Following Fuzzy Controller for a Mobile Robot," IEEE, 2011.

[10] Nazim Mir-Nasiri, "Camera-based 3D Object Tracking and Following Mobile Robot," IEEE, 2006.

[11] Suryono, Jadmiko Endo Susono Agus Syafrudin, "Rancang Bangun Geberator Pulsa Gelombang Ultrasonik dan Implementasinya untuk Pengukuran Antara Dua Objek," Berkala Fisika, pp. 29-31, April 2008.

[12] OLYMPUS. (2006) Ultrasonic Tranducers Technical Notes. [Online]. https://www.olympusims.com/data/File/panametrics/UT-technotes.en.pdf

[13] Slamet Hani, "Sensor Ultrasonik SRF05 Sebagai Pemantau Kecepatan Kendaraan Bermotor," Jurnal Teknologi, pp. 120-128, Desember 2010.

[14] Lilik Gunarta. (2011, Sep.) [Online]. http://skp.unair.ac.id/repository/GuruIndonesia/SENSORULTRASONIK_lilikgunarta_12436.pdf

[15] N. Gunasekaran, S. Rama Reddy, K. V. S. S. S. S. Sairam, "Bluetooth in Wireless Communication," IEEE Communication Magazine, june 2002.

[16] Motor Servo. [Online]. http://www.mdp.ac.id/materi/2011-2012-1/TK322/041035/TK322-041035-859-21.pdf

[17] Introduction to Servos. [Online]. http://www.rkessler.com/AdvRobotics-Embedded/Lessons/Lesson4/Intro2Servos.pdf 